\section{Relation of cyclic guanosine monophosphate and cyclic adenosine monophosphate in reducing the toxic effects of protamine administration} To the Editor:

We read with great interest the article by Raikar and associates ${ }^{1}$ regarding nitric oxide inhibition to relieve the adverse effects of protamine on blood pressure. They declared that hypotension caused by protamine administration can be blocked by nitrous oxide inhibition. We would like to add our experience to their information.

Adverse effects of protamine administration on various organ systems have been known for a long time. These changes were attributed to the increased complement levels associated with an increase in thromboxane and leukotriene levels. These mediators may impair the function of organs such as the heart and lungs, although these changes are mostly clinically insignificant. $\mathrm{We}^{2}$ documented that leukotriene and thromboxane levels increased after heparin reversal with protamine. These changes, which were associated with an increase in cyclic guanosine monophosphate (cGMP) levels and a reduction in cyclic adenosine monophosphate (cAMP) levels, adversely affected myocardial function. Monitoring cardiac output with a fast-response thermistor allowed us to calculate the ejection fraction changes in the right ventricle. After protamine administration, while right ventricular end-diastolic volume became stable, right ventricular end-systolic volume increased significantly, indicating the same degree of impairment in myocardial contractility. However, we did not observe any significant change in pulmonary artery pressure. These pressure changes were associated with a temporary defect in myocardial oxidative metabolism, as indicated by the changes in myocardial oxygen consumption and myocardial lactate extraction. Prostacyclin usage reduced the toxic mediator release and improved myocardial function. After protamine administration, we observed that protamine use decreased the cGMP level in the blood and increased the cAMP level in the blood. ${ }^{2,3}$ In light of this study, we hypothesized that a fall in cAMP level and a rise in cGMP level are responsible for the toxic manifestations of heparin reversal with protamine, similar to our observation during ischemic reperfusion. ${ }^{4}$ On the basis of this information, we used aminophylline, a phosphodiesterase inhibitor, to increase the cAMP level and observed that aminophylline use reduced the toxic mediator release and preserved myocardial function. ${ }^{5} \mathrm{Fi}-$ nally, adverse effects of protamine on myocardial function can be controlled with agents that increase the cAMP level.

S. Fehmi Katircioğlu, $M D$ Oğuz Taşdemir, $M D$

Kemal Bayazit, $M D$

Department of Cardiovascular Surgery Turkiye Yüksek htisas Hastanesi Ankara, Turkey

\section{REFERENCES}

1. Raikar GV, Hisamochi K, Raikar BL, Schaff HV. Nitric oxide inhibition attenuates systemic hypotension producecd by protamine. J Thorac Cardiovasc Surg 1996;111;1240-7

2. Katircioğlu SF, Küçükaksu DS, Bozdayi M, et al. Effects of prostacyclin on heparin reversal with protamine. Vascular Surgery 1992;8:464-472.

3. Katircioğlu SF, Küçükaksu DS, Taşdemir O, et al. Arachidonic acid metabolism after heparin reversal with protamine. Ann Thorac Surg 1995;59:550-1.

4. Katircioğlu SF, Küçükaksu DS, Bozdayi M, et al. Beneficial effects prostacyclin treatment on reperfusion of the myocardium. Cardiovasc Surg 1995;3:405-408.

5. Katircioğlu SF, Küçükaksu DS, Bozdayi M, et al. Benefical effects of aminophylline administration on heparin reversal with protamine. Jpn J Surg 1994;24:99-102.

$12 / 8 / 78748$

\section{Reply to the Editor:}

We appreciate the comments of Dr. Katircioğlu and his colleagues. As noted in their letter, the adverse effects of protamine may be mediated through a variety of mechanisms, including the complement system. In our study, we measured the serum level of cyclic guanosine monophosphate (cGMP) and found no significant change with the administration of protamine. Therefore we could not conclude that a fall in the cGMP level correlated with the adverse effects of protamine. This investigation focused on inhibition of the nitric oxide pathway, which decreased the systemic hypotension produced by protamine administration.

Attempts to attenuate the adverse effects of protamine have met with variable degrees of success. There may be several effectors of the systemic effects of protamine, and these mechanisms might be expected to cause different clinical manifestations during protamine reversal of heparin.

Goya V. Raikar, $M D$

Hartzell $V$. Schaff, $M D$

Section of Cardiovascular Surgery

Mayo Clinic

200 First St. SW

Rochester, MN 55905

12/8/78749

\section{Is left ventricular outflow tract obstruction really relieved on long-term follow-up?}

\section{To the Editor:}

Luciani and associates ${ }^{1}$ report good results in their article titled "One-Stage Repair of Interrupted Aortic Arch, Ventricular Septal Defect, and Subaortic Obstruction in the Neonate: A Novel Approach." However, I am unsure about the long-term results.

I treated a baby girl, not a neonate, who had a simple ventricular septal defect (VSD) associated with infundibular posterior malalignment, which caused only a $30 \mathrm{~mm}$ $\mathrm{Hg}$ pressure gradient through the left ventricular outflow tract (LVOT). Preoperative echocardiographic examination showed that she had a large perimembranous VSD with a mild pressure gradient between the left ventricle and ascending aorta, which resulted from posterior malalignment of the infundibular septum to the LVOT. Cardiac catheterization showed that the right ventricular/ left ventricular pressure ratio was 0.9 and the pressure gradient through the LVOT was only $30 \mathrm{~mm} \mathrm{Hg}$. Cardiac angiography also showed that the infundibular septum significantly deviated to the LVOT and the ascending aorta was relatively small $(6 \mathrm{~mm})$.

The patient was treated with catecholamines for cardiac 
failure caused by pulmonary hypertension, but her respiratory distress progressed. Because of her low weight (2850 $\mathrm{gm}$ ) and mild pressure gradient through the LVOT $(30 \mathrm{~mm}$ $\mathrm{Hg}$ ), we merely closed the VSD through the right atrium after inducing cardiac arrest with a crystalloid cardioplegic solution when she was 2 months of age. On closure of the VSD, a Dacron patch was attached with interrupted 5-0 polypropylene sutures. Stay sutures placed on the infundibular side of the VSD were inserted from the left side of the conal septum to the upper margin of the VSD. Moreover, we used as small a patch as possible for closure of the VSD to prevent protrusion of the patch into the LVOT and to pull the conal septum toward the right ventricular side.

The baby's postoperative course was uneventful. No pressure gradient in the LVOT was found, and the protrusion of the infundibular septum into the LVOT was completely repaired, as revealed by the echocardiographic examination before her discharge. However, follow-up echocardiography showed that the subaortic stenosis, which caused a pressure gradient of $30 \mathrm{~mm} \mathrm{Hg}$, had recurred 1 year after the operation. This gradient gradually increased because of the development of subaortic stenosis associated with hypertrophy of the conal septum at the left ventricular side. Three years after the operation, cardiac catheterization was performed and the pressure gradient was found to be $80 \mathrm{~mm} \mathrm{Hg}$. Consequently, I think that the hypertrophic subaortic muscle will need to be resected in the near future.

With Bove and colleagues, ${ }^{2}$ I now believe that when the infundibular septum malaligns with the LVOT, resulting in subaortic stenosis, the septum should be resected, with care taken to avoid injuring the aortic valve at the initial operation. This should be done even if the cardiac anomaly is complex and the pressure gradient is mild.

Kouichi Hisatomi, MD Second Department of Surgery Faculty of Medicine Kagoshima University 8-35-1 Sakuragaoka. Kagoshima City, Japan

\section{REFERENCES}

1. Luciani GB, Ackerman RJ, Chang AC, Wells WJ, Starnes VA. One-stage repair of interrupted aortic arch, ventricular septal defect, and subaortic obstruction in the neonate: a novel approach. J Thorac Cardiovasc Surg 1996;111:348-58.

2. Bove EL, Minich LL, Pfidjian AK, et al. The management of severe subaortic stenosis, ventricular septal defect, and aortic arch obstruction in the neonate. $\mathbf{J}$ Thorac Cardiovasc Surg 1993;105:289-96.

$12 / 8 / 78757$

\section{Reply to the Editor:}

I read Dr. Hisatomi's case report with interest. Dr. Hisatomi's patient had a ventricular septal defect (VSD) and subaortic stenosis as a result of the realignment of the infundibular septum. Although her anatomy is similar to that of the neonates we reported on with interrupted aortic arch and subaortic stenosis, she clearly belongs to a different subset of patients. Dr. Hisatomi describes the successful repair of the VSD with the attachment of the VSD sutures along the left side of the superior margin of the infundibular septum. By downsizing the patch and anchoring the superior margin of the patch to the left of the septum, Dr. Hisatomi successfully closed the VSD and relieved the left ventricular outflow tract obstruction that existed before the operation. In follow-up, he noted the recurrence of the subaortic gradient to a level of $80 \mathrm{~mm} \mathrm{Hg}$. He now concludes that he will need to reoperate to relieve the subaortic obstruction and theorizes that he should have performed this procedure at the first operation.

I agree with Dr. Hisatomi's conclusion that another operation is needed to relieve the subaortic obstruction. However, I disagree with his deduction based on one case that his previous operation was unsuccessful. In review of the literature, the recurrence rate of subaortic obstruction after different forms of repair, including resection of the infundibular membrane, has varied from $17 \%$ to $67 \%$ (peak gradient $>25 \mathrm{~mm} \mathrm{Hg}) .^{1-4}$ In our report, there was no early or midterm (14 months) recurrence in a group of neonates with subaortic areas with Z values greater than 4 deviations below the normal values. I believe this case report is of interest, but it would not persuade me to change my technique. Further, VSD closure without resection of the infundibulum, placing the sutures on the left superior margin of the VSD and downsizing the patch, has permitted excellent survival $(100 \%)$ in our current series with good midterm relief of subaortic stenosis. A risk factor for the recurrence of aortic and subaortic obstruction may be the size of the aortic valve anulus and whether or not it is bicuspid. We have noted recurrence of obstruction in three infants referred to our center who have had aortic annular dimensions less than $5 \mathrm{~mm}$ and a bicuspid valve at the initial operation. We are following this group of infants with interest.

In conclusion, these infants represent a difficult subset of patients. We need to define a more consistent way of repairing the VSD with acceptable morbidity and mortality that can be reproduced by many different centers. I believe the operation advocated in our article can be reproduced by many centers with good results.

Vaughn A. Stames, $M D$

Children's Hospital of Los Angeles Division of Cardiothoracic Surgery

USC School of Medicine

1510 San Pablo St., Suite 415

Los Angeles, CA 90033-4612

\section{REFERENCES}

1. Van Praagh R, Bernhard WF, Rosenthal A, Parisi LF, Fyler DF. Interrupted aortic arch: surgical treatment. Am J Cardiol 1971:27:200-11.

2. Jonas RA, Quaegebeur JM, Kirklin JW, Blackstone EH, Daicoff $G$, the Congenital Heart Surgeons Society. Outcomes in patients with interrupted aortic arch and ventricular septal defect: a multiinstitutional study. J Thorac Cardiovasc Surg 1994;107:1099-113.

3. Norwood WI, Ling P, Castaneda AR, Hougen TJ. Reparative operations for interrupted aortic arch with ventricular septal defect. J Thorac Cardiovasc Surg 1983;86:832-7.

4. Scott WA, Rocchini AP, Bove EL, Behrendt DM, Beekman 